\title{
PREDICTING BODY-CORE TEMPERATURE IN FISH SUBJECTED TO FLUCTUATING AMBIENT TEMPERATURE ${ }^{1}$
}

\author{
ROBERT G. FECHHELM² AND WILLIAM H. NEILL \\ Department of Wildlife and Fisheries Sciences, Texas A\&M University, \\ College Station, Texas 77843 \\ (Accepted 11/4/81)
}

A simulation model, based on Newton's law of cooling, was developed to predict body-core temperature in fish subjected to fluctuating ambient temperature. Under the model, body temperature "decays" exponentially, with rate coefficient $k$, toward

the equilibrium temperature that existed $L$ time units earlier. The latency period $L$ is presumably indicative of the time required for the initial transfer of heat between a fish's deep-body tissues and its external surfaces. The computerized model simulated body temperature at $10-\mathrm{s}$ intervals for comparison with that actually measured in five Lepomis macrochinus, two Tilapia aurea, and three $T$. nilotica as ambient temperature cycled irregularly between 18 and $33 \mathrm{C}$. The mean absolute error between observed and simulated body temperatures (411-540 comparisons per fish) ranged from $0.04 \mathrm{C}(145.9 \mathrm{~g} T$. nilotica) to $0.24 \mathrm{C}(89.6 \mathrm{~g} \mathrm{~T}$. nilotica). The maximum absolute error per series ranged from $0.14 \mathrm{C}(145.9 \mathrm{~g} T$. nilotica) to $0.67 \mathrm{C}(89.6 \mathrm{~g} T$. nilotica). Over $90 \%$ of the 4,564 prediction errors for the 10 fish were less than $\neq 0.3 \mathrm{C}$ (mean absolute error $=0.13 \mathrm{C}$ ). The parameters $k$ and $L$ were estimated for each fish from thermal step-change experiments that both preceded and followed the cyclic-temperature experiment. Precyclic estimates of $k$ were greater $(P<.01)$ than postcyclic estimates at both the genus and combined levels. Lepomis macrochirus warmed faster than they cooled $(P<.05)$. Data combined for the three species indicated a linear relationship between In $k$ and In weight, with slope -0.59 . Latency times were not correlated $(P>.10)$ with fish weight, nor did they differ $(P>.05)$ between pre- and postcyclic trials. In $L$. macrochirus, warming latency time was longer than cooling latency time $(P<.05)$.

\section{INTRODUCTION}

Newton's law of cooling (Kleiber 1972) has been used extensively to describe the rates at which poikilotherms thermally equilibrate with their environment (Bartholomew and Tucker 1963, 1964; Bartholomew and Lasiewski 1965; Stevens and Fry 1970, 1974; Weathers and White 1971; Spray and May 1972; Neill

\footnotetext{
${ }^{1}$ We thank Joe Folse, Bill Grant, Rich Noble, Peter Sharpe, and Wally Wu for critically reviewing the manuscript; Jim Matis and Howard Newton for their statistical advice; Bill Harvey for supplying the fish; and Jan Fechhelm for helping conduct the experiments. This research was funded through Texas Agricultural Experiment Station Project H-6295. This paper is Texas Agricultural Experiment Station Contribution no. TA 17330.

${ }^{2}$ Present address: L9L Ecological Research Assoc., 1410 Caviti St., Bryan, Texas 77801.
}

Physiol. Zool. 55(3):229-239. 1982.

(C) 1982 by The University of Chicago. All rights reserved. 0031-935X/82/5503-8137\$02.00 and Stevens 1974; Neill, Chang, and Dizon 1976; Stevens and Sutterlin 1976; Beitinger, Thommes, and Spigarelli 1977; Reynolds 1977; Spigarelli, Thommes, and Beitinger 1977; Pettit and Beitinger 1980). Newton's law, reformulated for appropriate application to living poikilotherms (Neill and Stevens 1974), states that the rate of change in an animal's body temperature is proportional to the difference between equilibrium and actual body temperatures:

$$
\frac{d T_{b}}{d t}=k \cdot\left[T_{\mathrm{e}}(t)-T_{\mathrm{b}}(t)\right]
$$

where $T_{\mathrm{b}}$ is the actual body temperature, $T_{\mathrm{e}}$ is the equilibrium temperature, $k$ is the rate coefficient, and $t$ is time. Thus, subsequent to any thermal disequilibration, body temperature exponentially approaches and eventually asymptotes with 
the equilibrium temperature at a rate determined by the constant $k$.

The equilibrium temperature equals the ambient temperature ( $\left.T_{2}\right)$ plus some excess temperature $\left(T_{x}\right)$ caused by the continuous addition of metabolic heat (Neill and Stevens 1974; Stevens and Fry 1974; Neill et al. 1976). Excess temperature itself may vary from fractions of a degree to as much as $20 \mathrm{C}$ depending on taxon, size, and the metabolic state of the individual (Bartholomew and Tucker 1963, 1964; Stevens and Fry 1970, 1971, 1974; Carey and Teal 1969; Carey et al. 1971; Neill et al. 1976; Smith 1976). The rate coefficient $k$, which can be defined as the instantaneous rate of change in body temperature per unit time per unit difference between $T_{\mathrm{e}}$ and $T_{\mathrm{b}}$, reflects the combined effects of direct thermal conduction through body mass, passive convection associated with intraand intercellular fluids, and forced convective transfer of heat via the cardiovascular system (Stevens and Sutterlin 1976; Beitinger et al. 1977 ; Reynolds 1977; Pettit and Beitinger 1980). The magnitude of $k$ may be expected to vary according to the animal's weight (Stevens and Fry 1974; Beitinger et al. 1977; Spigarelli et al. 1977), the specific location within the body at which $T_{\mathrm{b}}$ is measured (Spray and Belkin 1973; Stevens and Fry 1974; Neill et al. 1976), the direction of the $T_{\mathrm{e}}-T_{\mathrm{b}}$ differential (Bartholomew and Tucker 1963; Bartholomew and Lasiewski 1965; Weathers and White 1971; Beitinger et al. 1977; Spigarelli et al. 1977) and, in the case of certain poikilotherms tested in air, the degree of evaporative heat loss (Weathers and White 1971).

Despite the successful use of Newton's model to describe thermal transfer rates and to clarify some of the associated physiological mechanisms, few investigators have explored the model's short-term predictive capabilities. Kubb, Spotila, and Pendergast (1980), using derived estimates of $k$, have successfully predicted the body temperature in largemouth bass (Micropterus salmoides) subjected to step changes in ambient temperature. Neill and Stevens (1974) and Neill et al. (1976) developed a simulation model to predict $T_{\mathrm{b}}$ for tunas swimming in a thermal gradient, but sim- ulated results were not compared with independent data.

This paper presents the development of a simulation model, based on a modification of Newton's law with parameters estimated from step-change experiments, that predicts the body-core temperature of fish exposed to continuously fluctuating water temperature. Computerized simulations of transient body temperature are compared with actual core temperatures monitored during experiments.

\section{MATERIAL AND METHODS}

Lepomis macrochirus (bluegill) wëre electrofished from several small ponds in Brazos County, Texas, during summer 1979 and spring 1980. Tilapia aurea were obtained in fall 1979 and T. nilotica in spring 1980 from stocks at the Aquaculture Research Center of Texas A\&M University. Mixed populations of the three species were held under constant light at 21.5-22.5 $\mathrm{C}$ for a minimum of $6 \mathrm{wk}$ prior to testing.

For each experimental series, one fish was netted from the holding tank and implanted with a body-temperature transducer inserted through a 23-gauge hypodermic needle into the epaxial muscle mass just lateral to the fifth or sixth vertebra. The fish was then put into a soft-plastic mesh cage, which effectively restricted swimming movements but did not impair breathing actions or the circulation of water. The caged fish was suspended in a 12-liter circulating water bath at a constant temperature $( \pm 0.1 \mathrm{C})$ between 18.6 and $19.0 \mathrm{C}$ and left undisturbed for 90 $\min$.

The fish was subjected to a step-change increase in temperature by transferring it from the initial constant-temperature bath to another $( \pm 0.1 \mathrm{C})$ between 29.9 and 31.9 C. Body temperature was recorded every $5 \mathrm{~s}$ for the first minute after transfer and every $10 \mathrm{~s}$ thereafter until the fish reached its new equilibrium state. In all cases thermal equilibrium was defined as the lack of detectable body-temperature change in a period of $10 \mathrm{~min}$. The fish was then cooled by reversing the procedure. Two warming and two cooling trials were performed on each fish. 
Upon completion of the last step-change trial, the fish was allowed to equilibrate to a constant temperature $( \pm 0.1 \mathrm{C})$ between 18.8 and $21.5 \mathrm{C}$ for $20 \mathrm{~min}$. Then, bath temperature was fluctuated for 70-90 min by arbitrary additions of hot and cold water. Both body and water temperatures were recorded simultaneously every $10 \mathrm{~s}$ for the entire cyclic phase. Finally, the series of four (two warming and two cooling) step-change experiments was repeated. The fish was then weighed and returned to the original holding tank for observation. The entire procedure was performed on each of 10 fish-five bluegills (21.9$57.6 \mathrm{~g}$ ), two $T$. aurea (41.1 and $136.7 \mathrm{~g}$ ), and three $T$. nilotica $(18.6-145.9 \mathrm{~g})$.

Temperatures were monitored with two Bailey Instruments, Inc., digital thermometers (Model BAT-8), which display with $0.1 \mathrm{C}$ resolution. Data were read visually and recorded manually. The body-temperature probe was a Bailey Instruments, Inc., tissue-implantable, copper-constan$\tan$ thermocouple $0.076 \mathrm{~mm}$ in diameter (Type IT-23; time constant $=0.005 \mathrm{~s}$ ) . Water temperature was measured with a Bailey Instruments, Inc., 23-gauge needle thermocouple (Type MT-5; time constant $=0.15 \mathrm{~s}$ ).

The exponential rate coefficient $k$ was estimated for each of the eight step-change trials with each fish. Integrating equation (1) with respect to time gives

$$
\ln \left|T_{\mathrm{e}}-T_{\mathrm{b}}(t)\right|=\ln \left|T_{\mathrm{e}}-T_{\mathrm{b}}(0)\right|-k t,
$$

where $T_{\mathrm{b}}(t)$ is the body temperature at time $t$ and $T_{\mathrm{b}}(0)$ is the body temperature at $t$ $=0$. Thus, least-squares regression of $\ln$ $\left|T_{\mathrm{c}}-T_{\mathrm{b}}(t)\right|$ against time yielded a line with slope $-k$. The range of body temperatures employed in these calculations was truncated to eliminate both an initial period of thermal latency, during which the change in $T_{\mathrm{b}}$ appeared nonexponential, and errors induced by small fluctuations of body temperature (less than the resolution limits of the digital thermometer, $0.1 \mathrm{C}$ ) as it approached equilibrium (fig. 1). Body temperatures that occurred during the latency period and those recorded beyond the point at which $T_{\mathrm{b}}$ had spanned $80 \%$ of the difference between its initial and equilib- rium values were not used in the regression calculations. Consequently, for each stepchange trial, the first recorded value of $T_{\mathrm{b}}$ in the truncated range became $T_{\mathrm{b}}(0)$.

SIMULATION MODEL

Plots of $T_{\mathrm{b}}$ against time for the stepchange trials (e.g., fig. 1) revealed an initial lag in response similar to that observed by Crawshaw (1976), Neill et al. (1976), Reynolds (1977), and Spigarelli et al. (1977). We suspected that such response latency is indicative of the time required for the initial transport of heat via conductive and convective processes between the fish-water interfaces and the tissue in contact with the thermocouple. Assuming that this latency effect is of fixed duration $L$, then $T_{\mathrm{b}}$ would have had a constantly delayed reaction to any change in ambient temperature.

Newton's model, as defined in equation (1), was modified to account for response latency:

$$
\frac{d T_{\mathrm{b}}}{d t}=k \cdot\left[T_{\mathrm{e}}(t-L)-T_{\mathrm{b}}(t)\right] ;
$$

i.e., body temperature changes at a rate proportional to the difference between it-

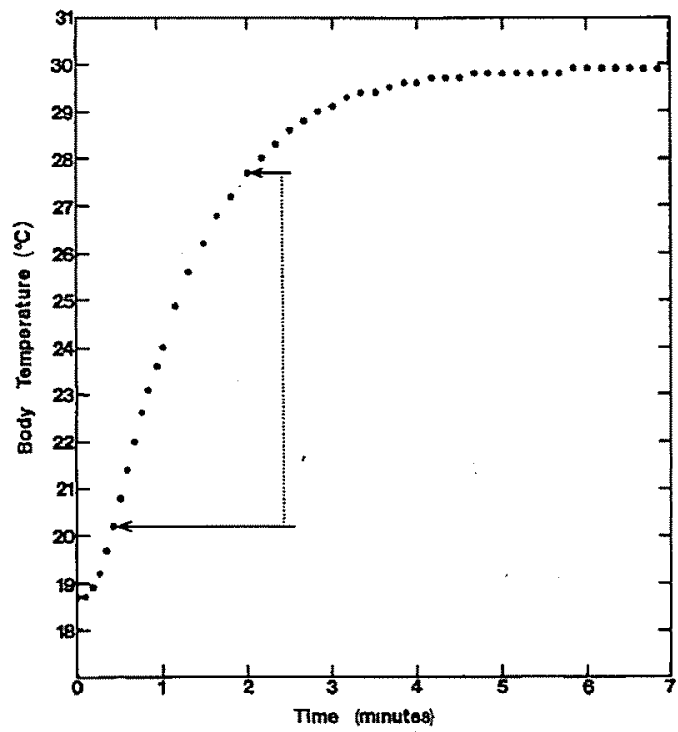

FIG. 1.-Body temperature versus time for an 18.6-g Tilapia nilotica (TN-3) subjected to a step change in ambient temperature, from $18.7 \mathrm{C}$ to 29.9 C. The values of body temperature between the arrows were used to estimate the exponential rate coefficient and latency period. 
self and the equilibrium temperature that existed $L$ time units earlier.

Latency periods were calculated from body-temperature series recorded during the step-change trials. Solving for $t$ in equation (3) (using the previously estimated value of $k$ and the known values of $T_{\mathrm{e}}(t)$ and $T_{\mathrm{b}}(0)$ for that particular warming or cooling trial) yielded the time of occurrence for a specific $T_{\mathrm{b}}(t)$ under conditions of true exponential decay. The difference between $T_{\mathrm{b}}(t)$ 's actual time of occurrence during a step-change trial and $T_{\mathrm{b}}(t)$ 's theoretical time of occurrence given true exponential decay was taken as a measure of latency period. Latency period was calculated for every recorded value of $T_{\mathrm{b}}(t)$ (within the truncated range, fig. 1) and its mean taken as the latency period for that particular warming or cooling trial. Latency periods were calculated for each of the eight step-change trials with each fish.

Equation (3) became the basis of our model for predicting body temperature under conditions of fluctuating ambient temperature. First, the changing equilibrium temperature was approximated as a piece-wise sequence of linear functions over consecutive time intervals of length $\Delta t$. Next, the incremental linear change in $T_{\mathrm{e}}$ was incorporated into equation (3), which then integrated to yield (see Appendix)

$$
\begin{aligned}
T_{\mathrm{b}}(t)= & T_{\mathrm{e}}(t-L)-\left(g_{\mathrm{e}} / k\right) \\
& +\left[T_{\mathrm{b}}(t-\Delta t)\right. \\
& -T_{\mathrm{e}}(t-\Delta t-L) \\
& \left.+\left(g_{\mathrm{e}} / k\right)\right] \cdot e^{-k \cdot \Delta e}
\end{aligned}
$$

where

$$
\begin{aligned}
g_{\mathrm{e}}= & {\left[T_{\mathrm{e}}(t-L)\right.} \\
& \left.-T_{\mathrm{e}}(t-\Delta t-L)\right] / \Delta t
\end{aligned}
$$

Equation (4) was applied recursively to generate a series of predicted body temperatures (at intervals of $\Delta t=10 \mathrm{~s}$ ) for each fish based on its mean $(N=8)$ value of $k$, mean $(N=8)$ value of $L$, and the $T_{\mathrm{e}}$ time series to which the fish was subjected. Since the calculated $T_{b}$ at any time $t$ depended, in part, upon the previously cal- culated value of $T_{\mathrm{b}}$ (or $\left.T_{\mathrm{b}}[t-\Delta t]\right)$, an initial estimate of body temperature was necessary. This was accomplished by allowing the fish to equilibrate to a constant ambient temperature before initiating cyclic fluctuations. Thus $T_{\mathrm{b}}$ at $t=0$ equaled $T_{\mathrm{e}}$.

In the case of our experiments, none of the fish registered an excess temperature; i.e., metabolic heat production in fish of the species and sizes we used had a negligible effect on body temperature and the dynamics of heat transfer. This simplified matters in that $T_{\mathrm{e}}=T_{\mathrm{a}}$ continuously; therefore the recursive model was applied directly to the $T_{\mathrm{a}}$ time series (all values of $T_{\mathrm{e}}$ in equations [4] and [5] were, in fact, values of $T_{\mathrm{a}}$ ).

The mean absolute error $(\Sigma \mid$ observed $T_{\mathrm{b}}$ - predicted $T_{\mathrm{b}} \mid / N, N=$ number of observations at consecutive $10-s$ intervals) was calculated as a measure of how well the predicted series fit the observed series. Predicted $T_{\mathrm{b}}$ series were also generated for a range of latency periods versus a range of rate coefficients. The resulting values of mean absolute error were plotted as a matrix and contoured to illustrate model robustness and to indicate the accuracy of rate coefficients and latency times estimated from the step-change experiments.

So that we could determine the importance of latency time as a predictor, $T_{\mathrm{b}}$ series also were simulated using the model uncorrected for $L$. The predictive accuracy of the $L$-uncorrected model then was compared with that of the full model.

Nonparametric analysis was performed on experimentally determined values of $k$ and $L$ using the Wilcoxen signed-ranks test (Siegel 1956). Comparisons were made between values determined before and after the cyclic portion of the experiment (mean precyclic cooling vs. mean postcyclic cooling; mean precyclic warming vs. mean postcyclic warming) and between warming and cooling runs. Because fish were alternately warmed and cooled, consecutive pairs of warming and cooling coefficients (or latency periods) were used in the paired analyses.

RESULTS

SIMULATION MODEL

Observed and modeled effects of fluctuating water temperature on body tem- 
perature are illustrated representatively in figure 2. Predicted body temperature, observed body temperature, and ambient water temperature are plotted against time for three fish to show cases of best (fig. $2 A$ ), intermediate (fig. $2 B$ ), and worst (fig. $2 C$ ) fit of the model. Summary data for all fish, including the mean values of $k$ and $L$ used in calculating predicted temperatures, appear in table 1. Goodness-of-fit ranged from a mean absolute error of $0.04 \mathrm{C}$ for a $145.9 \mathrm{~g}$ Tilapia nilotica (TN1, fig. $2 A$ ) to $0.24 \mathrm{C}$ for an $89.6 \mathrm{gg} T$. nil-. otica (TN-2, fig. $2 C$ ). The maximum absolute error per series ranged from $0.14 \mathrm{C}$ (TN-1) to $0.67 \mathrm{C}(\mathrm{TN}-2)$. Based on a total of 4,564 observations, encompassing the results from all 10 fish, over $90 \%$ of the prediction errors were within $\pm 0.3 \mathrm{C}$ (fig. $3 A$ ); overall mean absolute error $=0.13 \mathrm{C}$.

Contour plots of mean absolute error indicated the optimum combinations of $k$ and $L$ for predicted temperature-time series (fig. 4). Large prediction errors were caused by an inherently high mean absolute error in optimal cases (e.g., fig. 4A) and/or inaccurate estimates of $k$ or $L$ from the step-change trials (e.g., fig. $4 C$ ). The data from the fish yielding the poorest goodness-of-fit suffered from all three con- ditions (TN-2, fig. $4 D$ ). Assuming best estimates for $k$ and $L$, the optimal fit in terms of mean absolute error ranged from a low of $0.04 \mathrm{C}$ for TN-1 up to $0.20 \mathrm{C}$ for fish LM-4 (table 1).

Scrutiny of the ambient temperaturetime series and associated data suggested no consistent explanation to account for the differences in optimal goodness-of-fit or for differences in goodness-of-fit when mean values of $k$ and $L$ were used to stimulate body temperature.

Latency time determinations from stepchange experiments resulted in optimum values for five fish (e.g., fig. $4 A, 4 B$ ), 2-5-s overestimates in three fish (e.g., fig. $4 C$ ), and 4-6-s underestimates in two fish (e.g., fig. $4 D$ ). This implies that reasonably accurate estimates of $L$ can be determined from step-change experiments. The importance of latency period as a predictorvariable is indicated by the fact that had $L$ not been incorporated into the model, mean absolute error would have ranged from $0.21 \mathrm{C}(\mathrm{LM}-3)$ to $0.75 \mathrm{C}(\mathrm{TN}-2)$ with a maximum error range of $0.47 \mathrm{C}(\mathrm{TN}-1)$ to $1.64 \mathrm{C}(\mathrm{TN}-2)$. In addition, over $50 \%$ of the prediction errors $(N=4,564)$ would have exceeded $\pm 0.3 \mathrm{C}$ (fig. $3 B$ ).

The least-squares regression procedure

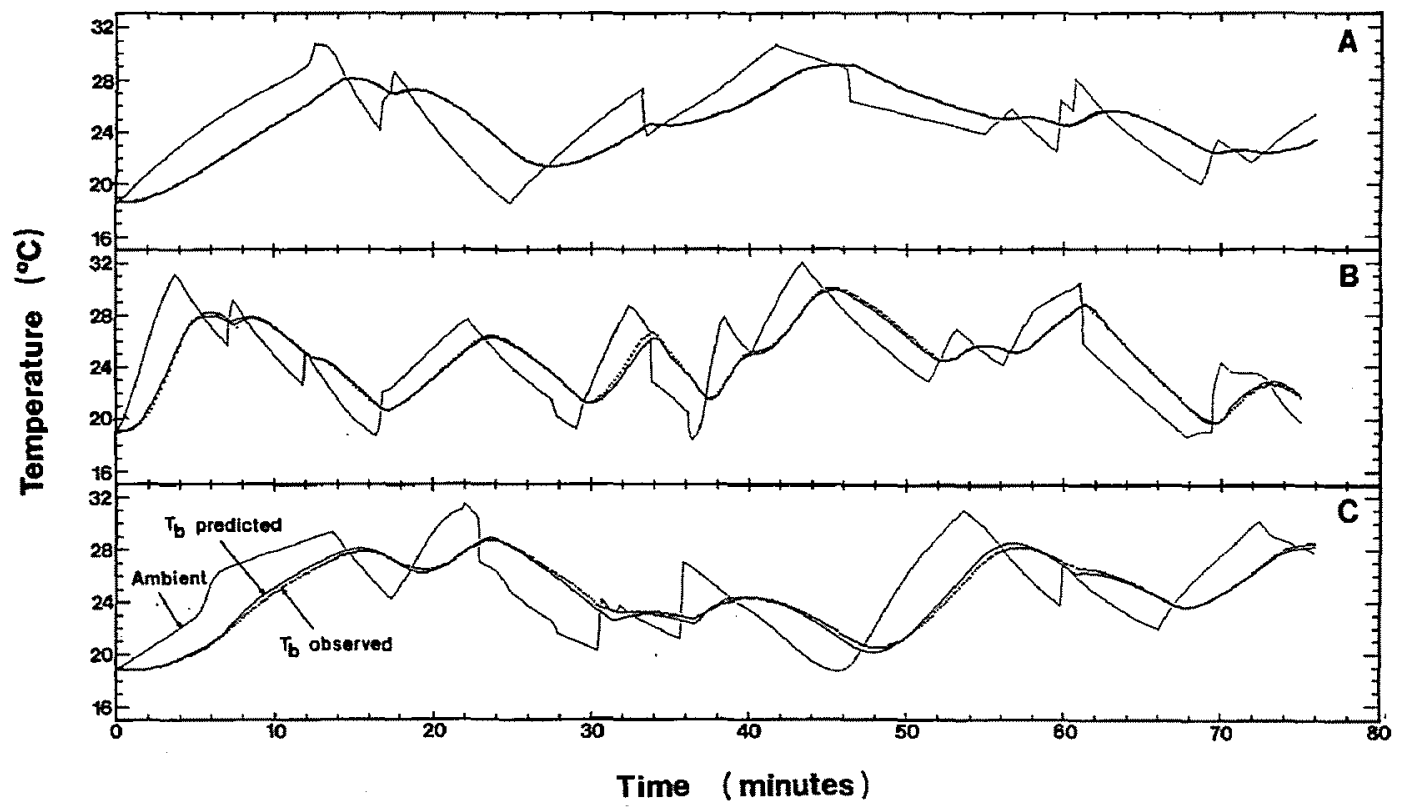

FIG. 2.-Predicted body temperature, observed body temperature, and ambient water temperature versus time for three fishes. A, Tilapia nilotica TN-1. B, Lepomis macrochirus LM-2. C, T. nilotica TN-2. These three examples were selected to show the cases of best $(A)$, intermediate $(B)$, and worst $(C)$ fit of the model. Ambient temperatures are plotted according to their actual times of occurrence. 
used in calculating $k$ was justified in that step-change estimates for four fish were optimum (e.g., fig. $4 A$ ), yielded underestimates of only $0.02-0.05 \mathrm{C} / \mathrm{min} \cdot \mathrm{C}$ for three fish (e.g., fig. $4 C$ ) and overestimates of 0.04-0.05 C/min - $\mathrm{C}$ for three fish (e.g., fig. $4 D$ ).

\section{COOLING AND WARMING STEP-CHANGE TRIALS}

Least-squares regression of $\ln \mid T_{\mathrm{e}}-$ $T_{\mathrm{b}}(t) \mid$ against time yielded a highly significant $(P<.01)$ linear fit, with a coefficient of determination $\left(r^{2}\right)$ greater than 0.99 , in each of the 80 step-change trials.

Significant differences $(P<.01)$ between pre- and postcyclic values of the rate coefficient $k$ occurred at the genus and combined species levels, with both warm- ing and cooling $k$ decreasing in magnitude during the second step-change series. For the entire data set, mean $\pm S D$ values of the postcyclic $k$ :precyclic $k$ ratio were 0.95 \pm 0.06 and $0.96 \pm 0.03$ for warming and cooling trials, respectively. Pre- and postcyclic latency times were not significantly different $(P>.05)$ at either the genus or combined levels.

Bluegill warmed significantly $(P<.01)$ faster than they cooled, resulting in a mean cooling/warming $k$ ratio of 0.94 . In contrast, $T$. aurea cooled significantly $(P<$ .05 ) faster than they warmed, the mean cooling/warming ratio being 1.07. Tilapla nilotica also tended to cool more rapidly than they warmed; however, the difference was not significant $(P>.05)$. Values of $L$

TABLE 1

COMPARISON OF MODELED AND OBSERVED RESULTS FOR THE CYCLIC TEMPERATURE EXPERIMENTS

\begin{tabular}{|c|c|c|c|c|c|c|c|c|}
\hline \multirow{2}{*}{\multicolumn{2}{|c|}{ FisH }} & \multirow[b]{2}{*}{$\begin{array}{c}\text { WEIGHT } \\
\text { (g) }\end{array}$} & \multirow[b]{2}{*}{$N$} & \multirow[b]{2}{*}{$\begin{array}{c}k\langle C / \min \cdot \mathrm{C}\rangle \\
\mathrm{MEAN} \pm \mathrm{SD} \\
\text { (Range) }\end{array}$} & \multirow[b]{2}{*}{$\begin{array}{c}L(\mathrm{sec}) \\
\text { MEAN }{ }^{2} \pm S D \\
(\text { Range) }\end{array}$} & \multicolumn{3}{|c|}{ ABSOLUTE ERROR (C) } \\
\hline & & & & & & $\begin{array}{c}\text { Mean; } \\
\text { Model } \\
\text { Corrected } \\
\text { for } L \\
\text { (Uncorrected } \\
\text { for } L \text { ) }\end{array}$ & $\begin{array}{l}\text { Maximum;c } \\
\text { Model } \\
\text { Corrected } \\
\quad \text { for } L \\
\text { (Uncorrected } \\
\quad \text { for } L)\end{array}$ & $\begin{array}{c}\text { Mean; }{ }^{\mathrm{b}} \\
\text { Model } \\
\text { with } \\
\text { Optimal } \\
\text { Estimates of } \\
k \text { and } L\end{array}$ \\
\hline \multicolumn{9}{|c|}{ Lepomis macrochimus: } \\
\hline LM-I & $\ldots \ldots \ldots$ & 55.1 & 432 & $\begin{array}{c}.52 \pm .04 \\
(.48-.59)\end{array}$ & $\begin{array}{r}16 \pm 3.18 \\
(10-21)\end{array}$ & $\begin{array}{l}.07 \\
(.32)\end{array}$ & $\begin{array}{l}.58 \\
(.79)\end{array}$ & .06 \\
\hline $\mathrm{LM}-2$ & $\ldots$ & 43.8 & 450 & $\begin{array}{c}.51 \pm .03 \\
(.46-.56)\end{array}$ & $\begin{array}{c}22 \pm 2.39 \\
(19-25)\end{array}$ & $\begin{array}{l}.14 \\
(.44)\end{array}$ & $\begin{array}{c}.58 \\
(1.30)\end{array}$ & .14 \\
\hline LM-3 & .. & 57.6 & 450 & $\begin{array}{c}.44 \pm .01 \\
(.42-.46)\end{array}$ & $\begin{array}{r}13 \pm 1.35 \\
(11-15)\end{array}$ & $\begin{array}{l}.16 \\
(.21)\end{array}$ & $\begin{array}{l}.59 \\
(.67)\end{array}$ & .15 \\
\hline LM-4 & . & 21.9 & 450 & $\begin{array}{l}.78 \pm .05 \\
(.73-.85)\end{array}$ & $\begin{array}{r}28 \pm 1.83 \\
(25-30)\end{array}$ & $\begin{array}{l}.20 \\
(.47)\end{array}$ & $\begin{array}{l}.56 \\
(.95)\end{array}$ & .20 \\
\hline LM-5 & .. & 34.9 & 450 & $\begin{array}{c}.55 \pm .02 \\
(.51-.57)\end{array}$ & $\begin{array}{r}26 \pm 2.00 \\
(23-29)\end{array}$ & $\begin{array}{c}.08 \\
(.36)\end{array}$ & $\begin{array}{l}.37 \\
(.76)\end{array}$ & .08 \\
\hline \multicolumn{9}{|c|}{ Tilapia aurea: } \\
\hline TA-1 & $\cdots$ & 41.1 & 411 & $\begin{array}{c}.55 \pm .02 \\
(.53-.57)\end{array}$ & $\begin{array}{r}28 \pm 1.77 \\
(26-32)\end{array}$ & $\begin{array}{l}.18 \\
(.48)\end{array}$ & $\begin{array}{c}.57 \\
(1.14)\end{array}$ & .07 \\
\hline $\mathrm{TA}-2$ & $\ldots \ldots \ldots \ldots$ & 136.7 & 540 & $\begin{array}{c}.26 \pm .02 \\
(.22-.29)\end{array}$ & $\begin{array}{c}33 \pm 11.21 \\
(12-43)\end{array}$ & .i2 & $\begin{array}{l}.51 \\
(.99)\end{array}$ & .11 \\
\hline \multicolumn{9}{|c|}{ Tilapia nilotica: } \\
\hline TN-1 & (n) & 145.9 & 456 & $\begin{array}{c}.27 \pm .01 \\
(.26-.28)\end{array}$ & $\begin{array}{r}23 \pm 2.64 \\
(20-28)\end{array}$ & $\begin{array}{l}.04 \\
(.22)\end{array}$ & $\begin{array}{l}.14 \\
(.47)\end{array}$ & .04 \\
\hline $\mathrm{TN}-2$ & $\ldots \ldots \ldots \ldots$ & 89.6 & 457 & $\begin{array}{c}.34 \pm .02 \\
(.29-.37)\end{array}$ & $\begin{array}{r}51 \pm 5.80 \\
(39-56)\end{array}$ & $\begin{array}{l}.24 \\
(.75)\end{array}$ & $\begin{array}{c}.67 \\
(1.64)\end{array}$ & .17 \\
\hline TN-3 & $\cdots \cdots$ & 18.6 & 468 & $\begin{array}{c}.93 \pm .02 \\
(.90-.96)\end{array}$ & $\begin{array}{c}18 \pm .71 \\
(17-19)\end{array}$ & $\begin{array}{l}.05 \\
(.35)\end{array}$ & $\begin{array}{l}.27 \\
(.82)\end{array}$ & .05 \\
\hline
\end{tabular}

Note.-The mean values of $k$ (rate coefficient) and $L$ (latency period) from step-change trials were the parameters used in simulating body temperature. Absolute error indicates how well the model was able to simulate the observed body-temperature time series. Absolute error, uncorrected for $L$, represents the goodness-of-fit obtained without incorporating latency period into the model. Mean absolute error, given optimal estimates of $k$ and $L$, provides a measure of best possible fit under the model. $N$ is the number of observations at consecutive 10-s intervals during each cyclic temperature experiment.

a $N=8$.

b $\left(\mathcal{\Sigma} \mid T_{\mathrm{b}}\right.$ observed $-T_{\mathrm{b}}$ predicted $\left.\mid\right) / N$.

c $\operatorname{Max}\left(T_{\mathrm{b}}\right.$ observed $-T_{\mathrm{b}}$ predicted $\left.\mid\right)$. 


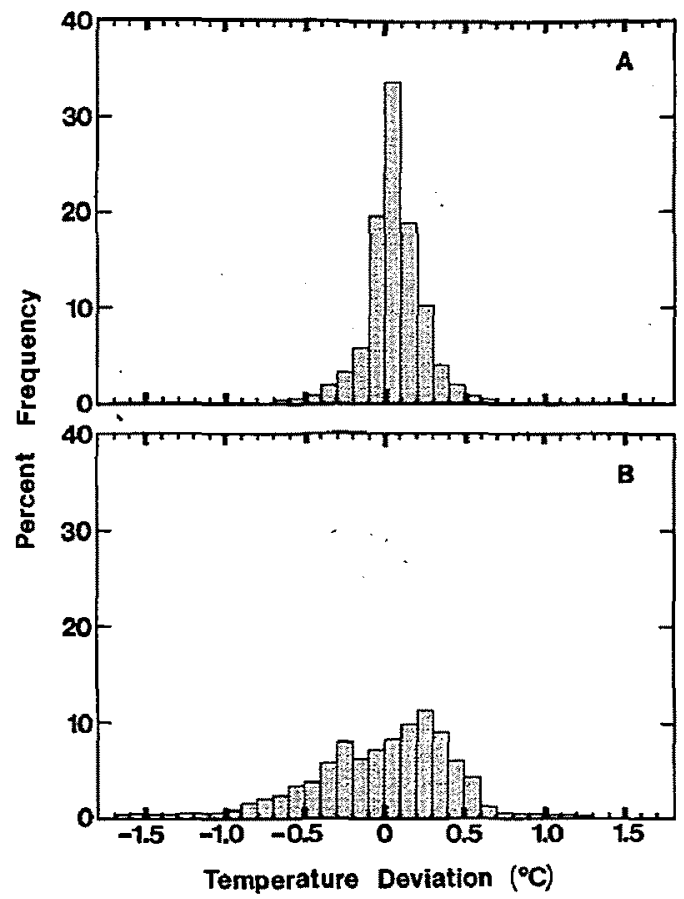

FIG. 3.-Frequency histograms of residual error (observed body temperature minus predicted body temperature) for the combined results of all $10 \mathrm{fish}$ $(N=4,564) . A$, The model corrected for latency period. $B$, The model not corrected for latency period.

for warming were greater than those for cooling in all species, but the difference was significant $(P<.05)$ only in bluegill.

A double logarithmic plot of the rate coefficient $k(\mathrm{C} / \mathrm{min} \cdot \mathrm{C}$, mean for each fish without regard for taxon) against weight (g) yielded a highly significant linear correlation: $\ln k=1.60-0.59$ ln weight; $P$ $<.01, r^{2}=0.99$ (fig. 5).

Latency times from combined data revealed no significant $(P>.10)$ linear relationship with weight (fig. 6). However, determinations of $L$ (seconds) for bluegill, when analyzed separately, showed a strong inverse linear correlation with weight: $L$ $=38.87-0.42$ weight; $P<.01, r^{2}=$ 0.93 .

\section{DISCUSSION}

The present study demonstrates that thermal exchange coefficients and associated latency periods derived from stepchange experiments provide an adequate basis for the prediction of body-core temperatures in tilapia and bluegill subjected

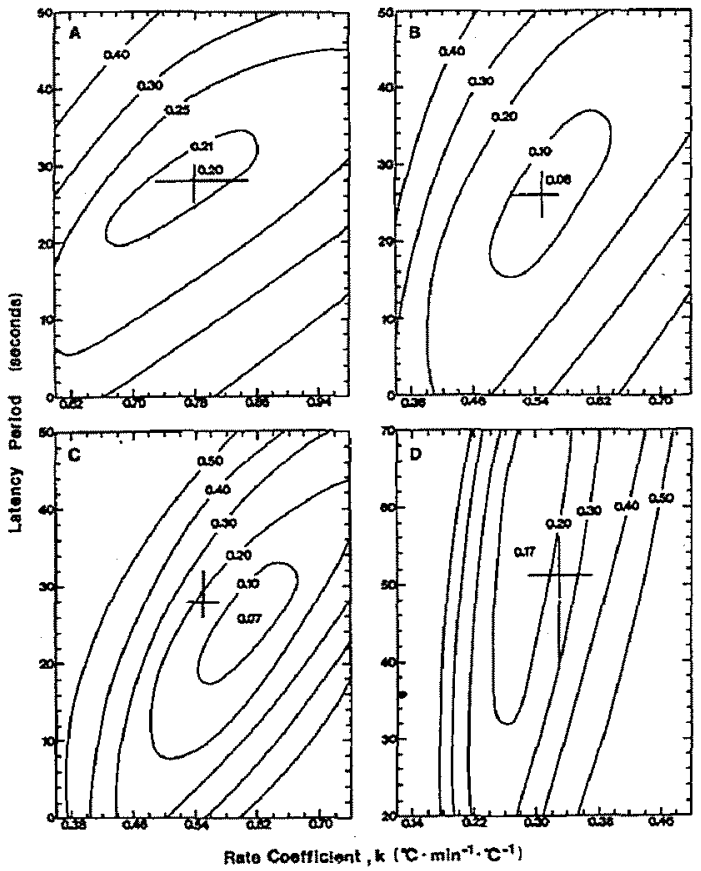

Fig. 4.-Contoured matrices of mean absolute error (degrees Celsius) between observed and predicted body temperatures for various combinations of rate coefficient and latency period in four fishes. $A, L e-$ pomis macrochirus LM-4. B, L. macrochimes LM-5. C, Tilapia aurea TA-1. D, T. nilotica TN-2. Horizontal and vertical bars represent, respectively, the range of rate coefficients $(N=8)$ and latency periods $(N=8)$ determined from step-change experiments. Their point of intersection indicates the mean value used in the simulation model to predict the bodytemperature series.

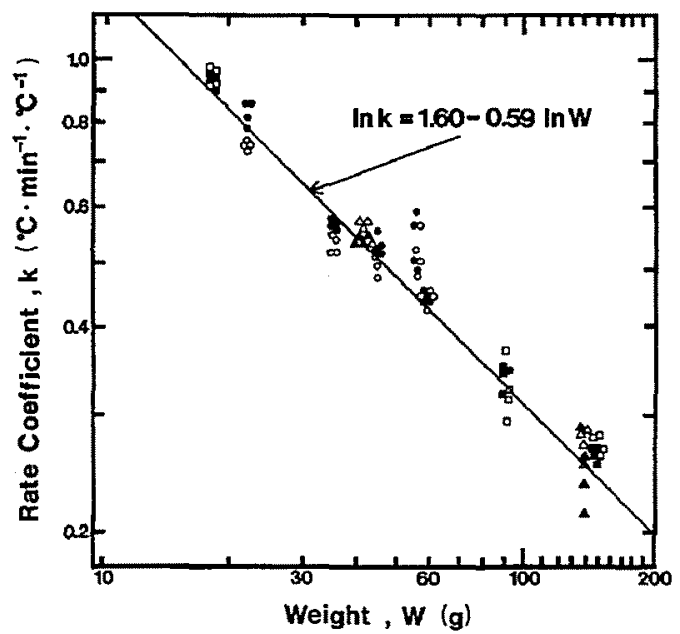

FIG. 5.-Double logarithmic plot of cooling (open symbols) and warming (solid symbols) values of the rate coefficient $k$ against body weight for Tilapia $n i$ lotica (squares), T. aurea (triangles), and Lepomis macrochirus (circles). Least-squares regression equation was calculated using the geometric mean $(N=$ 8) value of $k$ for each fish. 
to fluctuating ambient temperature. The model appears robust in that $90 \%(N=$ 4,564 ) of the predicted temperatures were within $\pm 0.3 \mathrm{C}$ (mean absolute error = $0.13 \mathrm{C}$ ) of the observed values, despite apparent temporal and physiological variation in $k$ and $L$. More than half of the prediction errors fell within the resolution limits of our experimental hardware, and in no case did an error exceed $0.7 \mathrm{C}$.

In fishes, the perception of thermal gradients and consequent thermoregulatory behavior may depend upon instantaneous differences between ambient and bodycore temperatures (Neill et al. 1976; Neill 1979; Stevens and Neill 1979). Such hypotheses are rendered testable by the development of a model for accurately predicting body temperature. Until now, core temperatures of a fish swimming in a thermal gradient could be known only by direct measurement with an implanted sensor. Normal thermoregulatory behavior is undoubtedly biased by stresses (e.g., surgical trauma and restriction of locomotory activity) associated with such a technique. Our model, appropriately parameterized, could obviate the need for telemetry of body temperature, provided only that the ambient temperature sequence generated by the fish can be monitored accurately.

Extension of our model to other poikilotherms is contingent upon several consid-

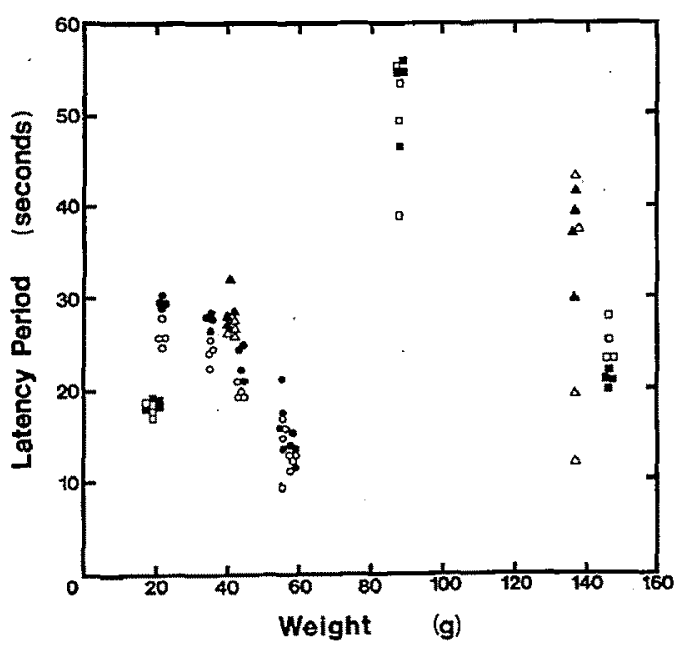

FIG. 6.-Plot of cooling (open symbols) and warming (solid symbols) latency times against body weight for Tilapia nilotica (squares), $T$. aurea (triangles), and Lepomis macrochirrs (circles). erations. Although cooling and warming rate coefficients varied significantly $(P<$ .05) in both Lepomis macrochirus and Tilapia aurea, the mean magnitudes of the cooling/warming ratios were very near unity, being 0.94 and 1.07 , respectively. Spigarelli et al. (1977) observed greater disparities, with cooling/warming ratios of 0.54 to 0.74 in brown trout (Salmo trutta), carp (Cyprinus carpio), and lake trout (Salvelinus namaycush). A mean ratio of 0.75 (in water) and 1.36 (in air) was calculated for two species of aquatic turtle, Pseudemys floridana and Chelydra serpentina (Weathers and White 1971). As much as a twofold difference has been reported for the marine iguana, Amblyrhynchus cristatus (Bartholomew and Lasiewski 1965). Even though the use of a single coefficient for both cooling and warming caused no noticeable impairment of prediction accuracy in the case of our experiments, larger species-specific rate differentials may disallow the use of a mean rate coefficient, requiring instead the incorporation of separate $k$ 's depending on whether the animal is being warmed or cooled.

Both warming and cooling rate coefficients were lower during postcyclic stepchange trials. This consistent, albeit small (approximately $5 \%$ ), increase in thermal inertia may have been related to the extended period $(>6 \mathrm{~h})$ of experimental stress endured by the fish. Cardiovascular responses are mediated by a number of variables that can both increase and decrease cardiac output (Randall 1968, 1970). The combined effects of handling, probe implantation, prolonged restraint, and temperature fluctuation may have caused fatigue-related decreases in cardiovascular activity. Any relative decrease in cardiac output would have reduced the convective heat transport via the circulatory system, thus decreasing the rate of thermal exchange. Stress was evident from observation of fish returned to holding tanks upon completion of the tests. Although there were no fatalities, the fish appeared disoriented and failed to exhibit normal escape responses when pursued. Seemingly normal behavior returned within several hours.

The tendency for bluegill to warm faster 
than they cool has been reported also for other fishes (Stauffer et al. 1975; Crawshaw 1976; Beitinger et al. 1977; Reynolds 1977; Spigarelli et al. 1977), lizards (Bartholomew and Tucker 1963; Bartholomew and Lasiewski 1965; Weathers 1970; McKenna and Packard 1975), turtles (Weathers and White 1971; Spray and May 1972), crocodilians (Grigg and Alchin 1976; Smith 1976), and snakes (Dmi'el and Borut 1972). Greater rates of heating than cooling have been attributed to endogenous heat production, variations in blood-flow distribution, and to heart-rate (HR) hysteresis that depends upon the direction of temperature change (at any given temperature, warming $H R>$ cooling HR). Neill et al. (1976), Kubb et al. (1980), and Pettit and Beitinger (1980), on the other hand, found no significant differences between warming and cooling rates in the skipjack tuna (Katsuwonus pelamis), the largemouth bass, and the South American lungfish (Lepidosiren paradoxa), respectively. Bethea (1972) even observed a heart-rate hysteresis (cooling/warming HR ratio $>1$ ) along with a cooling/warming $k$ ratio $>1$ in the turtle Terrapene ornata. Although our results for bluegill are consistent with the majority of published data, the more rapid cooling rates noted in our tilapia are not without precedent and further support the contention that the processes of thermal exchange vary among species.

The slope $(-0.59)$ of the double logarithmic plot of $k$ against weight is similar to those values reported for three species of Lake Huron sucker (Stevens and Fry 1974); the gizzard shad, Dorosoma cepedianum (Beitinger et al. 1977); and the combined data from eight species of Lake Michigan fishes (Spigarelli et al. 1977). Stevens and Fry (1970) noted a much smaller slope, -0.3, for Tilapia mossambica, but they later (Stevens and Fry 1974) attributed this to the inclusion of very small $(0.5-10-\mathrm{g})$ fish in their experiments. Truncation of Stevens and Fry's (1970) data to exclude fish weighing less than $10 \mathrm{~g}$ results in a $k$-weight slope much nearer -0.6 .

Analysis of data combined from the 10 fish revealed no significant linear $(P>.10)$ relationship between latency time and fish weight. Logically, $L$ should increase with fish weight, regardless of whether its magnitude depends more on passive or circulatory processes of heat transfer; however, one might anticipate a higher degree of variability associated with the latter mechanism owing to concomitant variation in heart rate, stroke volume, blood-pathway resistance, and blood distribution. In this respect, the excessive variance in the values of $L$ observed among several of our tilapia (fig. 6) may portend a major circulatory dependence. In addition, small inconsistencies in the placement of the temperature probe from one individual to another could create greater heat-flow discrepancies in a convective system due to discrete distribution of major blood vessels and capillary beds. This would further obscure the expected positive $L$-weight relationship.

The negative $L$-weight relationship in the bluegill was totally unexpected and, although it appears real, we feel that the narrow weight range (21.9-57.6 g) does not afford a definitive conclusion. Hypothetically, if this inverse relationship in bluegill is in fact real, and since conduction and passive convection distances increase with size, one must again suspect the existence of a strong association between latency time and forced convection which, by means of some as yet undefined mechanism, accounts for a reduction in $L$ as size increases. One possibility is an exponent relating weight and blood-flow time that is greater than the exponent relating weight and circulatory distance.

Further resolution of heat-exchange mechanisms in fishes demands elucidation of circulatory processes. Especially critical is knowledge of how temperature and temperature variation influence blood-flow rates and distribution among the pathways linking core tissues and the fish-water interfaces. It is only through such improved understanding of mechanisms that our semiempirical model can be superseded by one based more securely in biophysics.

\section{APPENDIX}

Approximating equilibrium temperature as a piece-wise sequence of linear functions over consecutive time intervals of length $\Delta t=t$ 
- $t_{0}$ enabled the rate of change in $T_{\mathrm{e}}$ over any particular interval to be defined as

$$
g_{e}=\left[T_{\mathrm{e}}(t)-T_{\mathrm{e}}\left(t_{\mathrm{o}}\right)\right] /\left(t-t_{\mathrm{o}}\right),
$$

and, by rearrangement,

$$
T_{\mathrm{e}}(t)=T_{\mathrm{e}}\left(t_{0}\right)+g_{\mathrm{e}} \cdot\left(t-t_{0}\right)
$$

Correcting equation (A2) to account for response latency gave

$$
\begin{aligned}
T_{\mathrm{e}}(t-L)= & T_{\mathrm{e}}\left(t_{0}-L\right) \\
& +g_{\mathrm{e}} \cdot\left(t-t_{0}\right) .
\end{aligned}
$$

Substituting this equation for $T_{\mathrm{e}}(t-L)$ in text equation (3) yielded

$$
\begin{aligned}
\frac{d T_{\mathrm{b}}}{d t}= & k \cdot\left[T_{\mathrm{e}}\left(t_{0}-l\right)\right. \\
& \left.+g_{\mathrm{e}} \cdot\left(t-t_{0}\right)-T_{\mathrm{b}}(t)\right] .
\end{aligned}
$$

Integrating equation (A4) with respect to time,

$$
\begin{aligned}
T_{\mathrm{b}}(t)= & T_{\mathrm{e}}(t-L)-\left(g_{\mathrm{e}} / k\right) \\
& +\left[T_{\mathrm{b}}\left(t_{\mathrm{o}}\right)-T_{\mathrm{e}}\left(t_{\mathrm{o}}-L\right)\right. \\
& \left.+\left(g_{\mathrm{e}} / k\right)\right] \cdot e^{-k \cdot\left(t-t_{0}\right)} .
\end{aligned}
$$

Eliminating $t_{0}(=t-\Delta t$, since $\Delta t$ is constant) to emphasize the recursive nature of the model,

$$
\begin{aligned}
T_{\mathrm{b}}(t)= & T_{\mathrm{e}}(t-L)-\left(g_{\mathrm{e}} / k\right) \\
& +\left[T_{\mathrm{b}}(t-\Delta t)\right. \\
& -T_{\mathrm{e}}(t-\Delta t-L) \\
& \left.+\left(g_{\mathrm{e}} / k\right)\right] e^{-k \cdot \Delta t},
\end{aligned}
$$

where

$$
\begin{aligned}
g_{\mathrm{e}}= & {\left[T_{\mathrm{e}}(t-L)\right.} \\
& \left.\leftarrow T_{\mathrm{e}}(t-\Delta t-L)\right] / \Delta t .
\end{aligned}
$$

\section{LITERATURE CITED}

BaRTHolomew, G. A., and R. C. LASIEWSKI. 1965. Heating and cooling rates, heart rate and simulated diving in the Galapagos marine iguana. Comp. Biochem. Physiol. 16:573-582.

Bartholomew, G. A., and V. A. TuCKER. 1963. Control of changes in body temperature, metabolism and circulation by the agamid lizard, $A m$ phibolurus barbatus. Physiol. Zool. 36:199-218.

- 1964. Size, body temperature, thermal conductance, oxygen consumption, and heart rate in Australian varanid lizards. Physiol. Zool. 37: 341-354.

BeItINGer, T. L., M. M. Thomiges, and S. A. SPIGARELLI. 1977. Relative roles of conduction and convection in the body temperature change of gizzard shad, Dorsoma cepedianum. Comp. Biochem. Physiol. A, Comp. Physiol. 57:275-279.

BETHEA, N. J. 1972. Effects of temperature on heart rate and rates of cooling and warming in Terrapene omata. Comp. Biochem. Physiol. A, Comp. Physiol. 41:301-305.

CAREY, F. G., and J. M. Teal. 1969. Regulation of body temperature by the bluefin tuna. Comp. Biochem. Physiol. 28:205-213.

CAREY, F. G., J. M. Teal, J. W. Kanwisher, and K. D. LAwSON. 1971. Warm-bodied fish. Amer. Zool. 11:137-145.

CrawsHaW, L. I. 1976. Effect of rapid temperature change on mean body temperature and gill ventilation in carp. Amer. J. Physiol. 231:837-841.

DMI'EL, R., and A. BoRUT. 1972. Thermal behavior, heat exchange, and metabolism in the desert snake Spalerosophis cliffordi. Physiol. Zool. 45:78-94.

GRIGG, G. C., and J. ALCHIN. 1976. The role of the cardiovascular system in thermoregulation of Crocodylus johnstoni. Physiol. Zool. 49:24-36.

KLEIBER, M. 1972. Body size, conduction for heat flow and Newton's law of cooling. J. Theoret. Biol. 37:139-150.

KubB, R. N., J. R. Spotila, and D. R. PenderGAST. 1980. Mechanisms of heat transfer and time-dependent modeling of body temperatures in the largemouth bass (Micropterus salmoides). Physiol. Zool. 53:222-239.

McKenna, G. M., and G. C. PaCkard. 1975. Rates of heat exchange in the lizards Cnemidophoms sexlineatus and Sceloporus undulatus. Copeia 1975:162-169.

NerlL, W. H. 1979. Mechanisms of fish distribution in heterothermal environments. Amer. Zool. 19:305-317.

NeILl, W. H., R. K. C. Chang, and A. E. Dizon. 1976. Magnitude and ecological implications of thermal inertia in skipjack tuna, Katsuronis pelamis (Linneaus). Environmental Biol. Fishes 1:61-80.

Neill, W. H., and E. D. Stevens. 1974. Thermal inertia versus thermoregulation in "warm" turtles and tunas. Science 184:1008-1010.

Petrit, M. J., and T. L. Beitinger. 1980. Thermal response of the South American lungfish, Lepidosiren paradoxa. Copeia 1980:130-136.

RANDALL, D. J. 1968. Functional morphology of the heart in fishes. Amer. Zool. 8:179-180.

. 1970. The circulatory system. Pages 133-172 in W. S. HoAR and D. J. RANDaLL, eds. Fish physiology. Vol. 4. The nervous system, circulation and respiration. Academic Press, New York. REYNOLDS, W. W. 1977. Thermal equilibration rates 
in relation to heart beat and ventilation frequency in largemouth bass, Micropterus salmoides. Comp. Biochem. Physiol. A, Comp. Physiol. 56:195-201.

SIEGEL, S. 1956. Nonparametric statistics for the behavioral sciences. McGraw-Hill, New York.

SMITH, E. N. 1976. Heating and cooling rates of the American alligator, Alligator mississippiensis. Physiol. Zool. 49:37-48.

Spigarelli, S. A., M. M. Thommes, and T. L. BEITINGER. 1977. Influence of body weight on heating and cooling of selected Lake Michigan fishes. Comp. Biochem. Physiol. A, Comp. Physiol. 56:51-57.

Spray, D. C., and D. B. BELKIN. 1973. Thermal patterns of heating and cooling of Iguano iguana and Ctenosaura hemilopha. Comp. Biochem. Physiol. A, Comp. Physiol: 44:881-892.

SpRAy, D. C., and M. L. MAY. 1972. Heating and cooling rates in four species of turtles. Comp. Biochem. Physiol. A, Comp. Physiol. 41:507-522.

Stauffer, J. R., K. L. Dickson, A. G. Heath, G. W. LANNe, and J. CaIrRNS, JR. 1975. Body temperature change of bluegill sunfish subjected to thermal shock. Progressive Fish-Cult. 37:90-92.
StEvens, E. D., and F. E. J. FRY. 1970. The rate of thermal exchange in a teleost. Tilapia mossambica. Can. J. Zool. 48:221-226.

1971. Brain and muscle temperature in ocean caught and captive skipjack tuna. Comp. Biochem. Physiol. A, Comp. Physiol. 38:203-211.

1974. Heat transfer and body temperature in non-thermoregulatory teleosts. Can. J. Zool. 52:1137-1143.

Stevens, E. D., and W. H. Neill. 1979. Body temperature relations of tunas, especially skipjack. Pages $316-359$ in W. S. HOAR and D. J. RANDALL, eds. Fish physiology. Vol. 8. Locomotion. Academic Press, New York.

Stevens, E. D., and A. M. SkutTerlin. 1976. Heat transfer between fish and ambient water. J. Exp. Biol. 65:131-145.

Weathers, W. W. 1970 . Physiological thermoregulation in the lizard Dipsosaumus dorsalis. Copeia 1970:549-557.

Weathers, W. W., and F. N. White. 1971. Physiological thermoregulation in turtles. Amer. J. Physiol. 221:704-710. 